\title{
H1N1 Infection Presenting as Acute Liver Failure in an Infant
}

\author{
Vijay Kumar $^{1}$ - Soumalya Chakraborty ${ }^{1}$ - BC Gowtham ${ }^{1}$. Surjeet Kumar ${ }^{1}$. Suresh Kumar Angurana ${ }^{1}$ (D) \\ Jayashree Muralidharan ${ }^{1}$
}

Received: 22 April 2020 / Accepted: 3 June 2020 / Published online: 11 June 2020

(C) Dr. K C Chaudhuri Foundation 2020

To the Editor: An 8-mo-old boy presented with fever, cough, and rapid breathing for $10 \mathrm{~d}$. At the referring hospital, he was admitted for $4 \mathrm{~d}$ and received oxygen, intravenous fluids, and antibiotics. On day 4 of admission, he developed one episode of generalized tonic-clonic seizure followed by encephalopathy and was referred to us. There was no history of aspirin intake. Examination revealed weight $7 \mathrm{~kg}(-1.06 \mathrm{Z}$ score), pulse $160 / \mathrm{min}$, gasping respiratory efforts, feeble peripheral pulses, $\mathrm{SpO}_{2} 82 \%$ on room air, pallor, no jaundice, and random blood glucose $43 \mathrm{mg} / \mathrm{dl}$. Central nervous system (CNS) examination revealed Glasgow Coma Scale (GCS) of 8 , no cranial nerve deficits, increased tone, brisk deep tendon reflexes, and upgoing planters. Respiratory examination revealed bilateral crepitations. A disseminated viral illness causing respiratory and CNS involvement was considered as the likely possibility. The treatment included positive pressure ventilation, intravenous fluids and antibiotics (ceftriaxone, cloxacillin, acyclovir, and oseltamivir), sedation-analgesia, phenytoin, and 3\% saline infusion. Investigations revealed hemoglobin $7.2 \mathrm{~g} / \mathrm{dl}$, total leukocyte count (TLC) 8600/cu $\mathrm{mm}$, platelet count $2,50,000 / \mathrm{cu} \mathrm{mm}$, Serum glutamic oxaloacetic transaminase (SGOT) $4988 \mathrm{IU} / \mathrm{L}$, Serum glutamic pyruvic transaminase (SGPT) $3323 \mathrm{IU} / \mathrm{L}$, bilirubin $1.5 \mathrm{mg} / \mathrm{dl}$, prothrombin time (PT) $28 \mathrm{~s}$, activated partial thromboplastin time (APTT) $31 \mathrm{~s}$, international normalized ratio (INR) 2.8, serum ammonia $252 \mu \mathrm{mol} / \mathrm{L}$, and normal renal function test. Chest radiograph revealed interstitial infiltrates. Nasopharyngeal swab tested positive for H1N1 by RT-PCR. Hepatitis A, B, C, E, Epstein Barr virus, and Herpes simplex virus serologies were negative. The CSF analysis (on day 3 ) and CT head were normal. Further, rifaximin and lactulose

Suresh Kumar Angurana

sureshangurana@gmail.com

1 Division of Pediatric Critical Care, Department of Pediatrics, Advanced Pediatrics Centre, Postgraduate Institute of Medical Education and Research (PGIMER), Chandigarh 160012, India were added. He showed gradual improvement in clinical and biochemical parameters, was extubated on day 5 , received oseltamivir for $7 \mathrm{~d}$, and discharged on day 8 , and had pre-morbid neurological status on 3 mo follow-up.

H1N1 (Influenza A) is usually an acute and self-limited respiratory illness. The severe cases can present with pneumonia, acute respiratory distress syndrome, septic shock, neurological involvement, myocardial dysfunction, and multiorgan failure [1]. H1N1 with liver involvement is rarely reported in children and accounts for $<3 \%$ of all H1N1 cases [2-5]. The liver involvement in $\mathrm{H} 1 \mathrm{~N} 1$ is believed to be due to overproduction of pro-inflammatory cytokines leading to changes in hepatic metabolism and enzyme activity, increased hepatic oxidative stress, decreased antioxidant defences, and damage by viral antigens rather than the direct viral invasion [6]. Whitworth et al. reported 4 children (aged 14-39 mo) with influenza A presenting as acute hepatitis and who recovered with supportive therapy [3]. Li et al. reported 2 children with severe influenza A (H3N2) with hepatic dysfunction who were treated with supportive treatment, mechanical ventilation, high dose corticosteroids, and gamma globulin; and one child died [5]. To best of our knowledge, this is the first report of acute liver failure in a child with H1N1 infection from India.

\section{Compliance with Ethical Standards}

Conflict of Interest None.

\section{References}

1. Halasa NB. Update on the 2009 pandemic influenza A H1N1 in children. Curr Opin Pediatr. 2010;22:83-7.

2. Carrillo-Esper R, Perez-Bustos E, Ornelas-Arroyo S, AlboresSaavedra J, Uribe M. Liver involvement in severe human influenza A H1N1. Ann Hepatol. 2010;9:107-11.

3. Whitworth JR, Mack CL, O'Connor JA, Narkewicz MR, Mengshol $\mathrm{S}$, Sokol RJ. Acute hepatitis and liver failure associated with 
influenza A infection in children. J Pediatr Gastroenterol Nutr. 2006;43:536-8.

4. Noor A, Gradidge E. A case of Reye syndrome caused by influenza A virus. Ochsner J. 2018;18:425-7.

5. Li T, Qi N, Gao X, Yu H. Rescue of four pediatric patients with severe influenza A (H3N2) in Weifang, China. J Int Med Res. 2018;46:4800-5.
6. Papic N, Pangercic A, Vargovic M, Barsic B, Vince A, Kuzman I. Liver involvement during influenza infection: perspective on the 2009 influenza pandemic. Influenza Other Respir Viruses. 2012;6: e2-5.

Publisher's Note Springer Nature remains neutral with regard to jurisdictional claims in published maps and institutional affiliations. 